\title{
Effects of tightening speed on torque coefficient in lag screw timber joints with steel side plates
}

\author{
Doppo Matsubara ${ }^{1}$ - Yoshiaki Wakashima ${ }^{2} \cdot$ Yasushi Fujisawa $^{2} \cdot$ Hidemaru Shimizu $^{3} \cdot$ Akihisa Kitamori $^{4}$. \\ Koichiro Ishikawa ${ }^{5}$
}

Received: 13 September 2017 / Accepted: 10 November 2017 / Published online: 12 December 2017

(c) The Japan Wood Research Society 2017

\begin{abstract}
To investigate the effects of tightening speed on the torque coefficient in lag screw timber joints with steel side plates, tightening tests were conducted on main timber members made from Cryptomeria japonica, Chamaecyparis obtusa and Pseudotsuga menziesii, under four tightening speed conditions (1, 4, 10, and $20 \mathrm{rpm})$. Major stick-slip behavior was observed in $C$. obtusa based on the relationship of tightening angle with clamp force, tightening torque, and thread torque at tightening speeds of 1 and $4 \mathrm{rpm}$. In addition, tightening speed's effects on the torque coefficient $(K)$ varied depending on the wood species of the main member. In P. menziesii, $K$ was not affected by the tightening speed: the ratio of torque expended on tightening was $25 \%$ on average, and the ratio of torque expended on bearing surface friction was higher than the ratio of torque expended on thread friction.
\end{abstract}

Keywords Lag screw $\cdot$ Tightening speed $\cdot$ Torque coefficient $\cdot$ Frictional coefficient

\section{Introduction}

As the designs for timber structures grow larger and larger, contractors are increasingly using lag screw connectors in their projects [1]. The benefits of lag screw joints include less loosening and slippage when a load is first applied than bolted timber joints; however, they also require more caution, making construction management an important consideration [2]. For example, screwing in a lag screw without first drilling a pilot hole can cause the timber member to crack, or driven in using a hammer. In addition, overtightening beyond a lag screw's pullout strength risks damaging the

Doppo Matsubara

matsubara.doppo@iri-tokyo.jp

1 Tokyo Metropolitan Industrial Technology Research Institute, 2-4-10, Aomi, Koto-Ku, Tokyo 135-0064, Japan

2 Toyama Prefectural Agricultural, Forestry and Fisheries Research Center, 4940, Imizu, Toyama 939-0311, Japan

3 Sugiyama Jogakuen University, 17-3, Chikusa-ku, Nagoya, Aichi 464-8662, Japan

4 Research Institute for Sustainable Humanosphere, Kyoto University, Uji, Kyoto 611-0011, Japan

5 University of Fukui, 3-9-1, Fukui, Fukui 910-8507, Japan joint, weakening it compared with its original performance. One potential solution to prevent the latter scenario is to apply a torque control method to provide suitable torque by means of a torque wrench or other tool. However, no one has yet developed a torque control method for lag screw timber joints: contractors today rely on their own experiences and intuition when tightening lag screw connectors, an arbitrary judgment. Torque control methods involve different tightening speeds, because tools such as torque wrenches and nut runners are turned manually to provide torque. For metallic bolted joints, differences in tightening speed are known to result in different coefficients of friction and torque, important factors that determine the feasibility of a given torque control method as well as in variation in axial force ("clamp force" below) [3]. In a previous study on bolted timber joints, we discovered that the torque coefficient decreases at higher tightening speeds and were able to reduce fluctuations in the clamp force by setting the tightening speed to $20 \mathrm{rpm}$ [4]. For lag screw timber joints, however, there appears to be no research that has clarified the effects of tightening speed on the torque coefficient. This point needs to be clarified, since construction management is more important for lag screw timber joints than for bolt joints, and because no torque control method has been established for lag screw timber joints. In a previous study, we developed a high 
Fig. 1 Tightening test method for lag screw timber joints

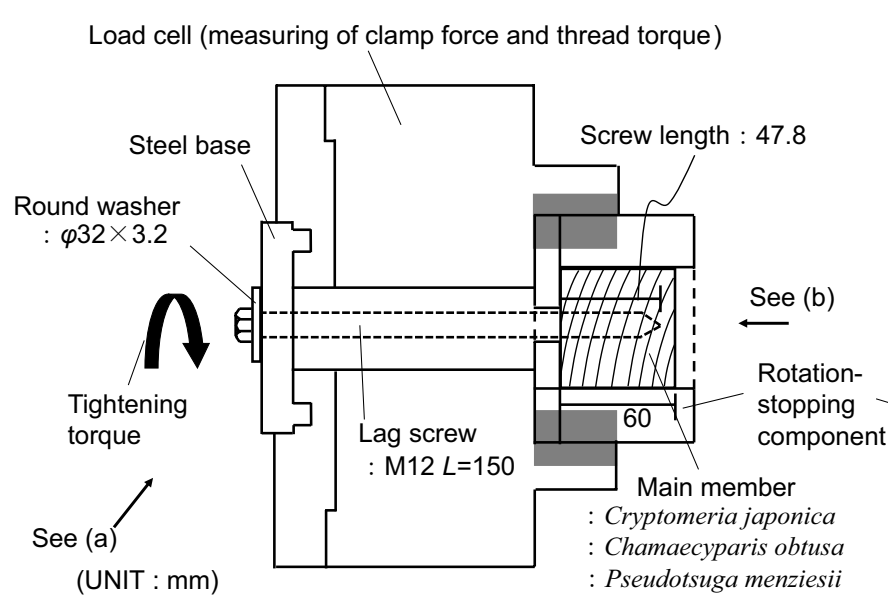

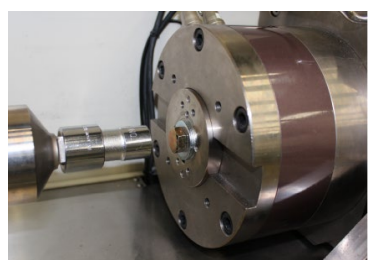

(a)

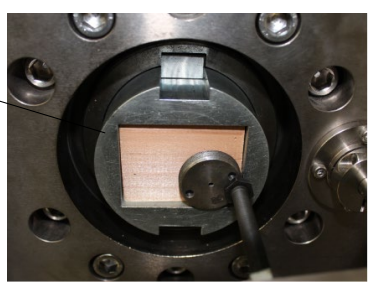

(b) damping shear wall in which timber members were joined together, or to steel plates, with lag screws or bolts. Tightening generates a clamp force, which in turn generates a frictional resistance force between two timber members, or between one and a steel plate [5]. Our later research investigated how to apply torque control methods to control this clamp force, a serious issue that must be addressed to control the expression of this frictional resistance force $[6,7]$. One of the resulting challenges we faced in developing our high damping shear wall was how to determine the effects of lag screw tightening speed on the joint's torque coefficient.

In the present study, using timber members made from three kinds of wood species, we subjected lag screw timber joints with steel side plates to tightening tests, with the aim of determining the effects of tightening speed and tree species on the torque coefficient.

\section{Materials and methods}

Figure 1 shows the experimental method. Lag screw timber joints with steel side plates were subjected to tightening tests using a bolt force tester (NST-500NM: Japan Instrumentation System Co., Ltd, Nara, Japan). Test specimens were composed of three parts: a main wooden member, a round washer, and a lag screw (Fig. 1). Main members were created from three conifers: Cryptomeria japonica, Chamaecyparis obtusa, and Pseudotsuga menziesii. Dimensions of the main member were 60 (Longitudinal direction) $\times 45 \times 60 \mathrm{~mm}$. Specimens were tested after curing in the laboratory for approximately 2 months at $20 \pm 2{ }^{\circ} \mathrm{C}$. A pilot hole of $\varphi 7.5$ and $55 \mathrm{~mm}$ deep was drilled in the main member. The relative humidity of the conditioning room ranged from 32 to $53 \%$ during the conditioning period (relative humidity was not strictly controlled). The density and moisture content of each specimen are shown in Table 1. The dimensions of the
Table 1 Basic properties of the test materials

\begin{tabular}{llc}
\hline Conifer species & Density $\left(\mathrm{kg} / \mathrm{m}^{3}\right)$ & $\begin{array}{l}\text { Moisture } \\
\text { content }(\%)\end{array}$ \\
\hline Cryptomeria japonica & & \\
Ave. & 351 & 11.5 \\
SD & 1.8 & 0.9 \\
Chamaecyparis obtusa & & \\
Ave. & 465 & 11.9 \\
SD & 11.3 & 1.0 \\
Pseudotsuga menziesii & & \\
Ave. & 466 & 10.4 \\
SD & 5.8 & 1.2 \\
\hline
\end{tabular}

Ave. average, $S D$ standard deviation

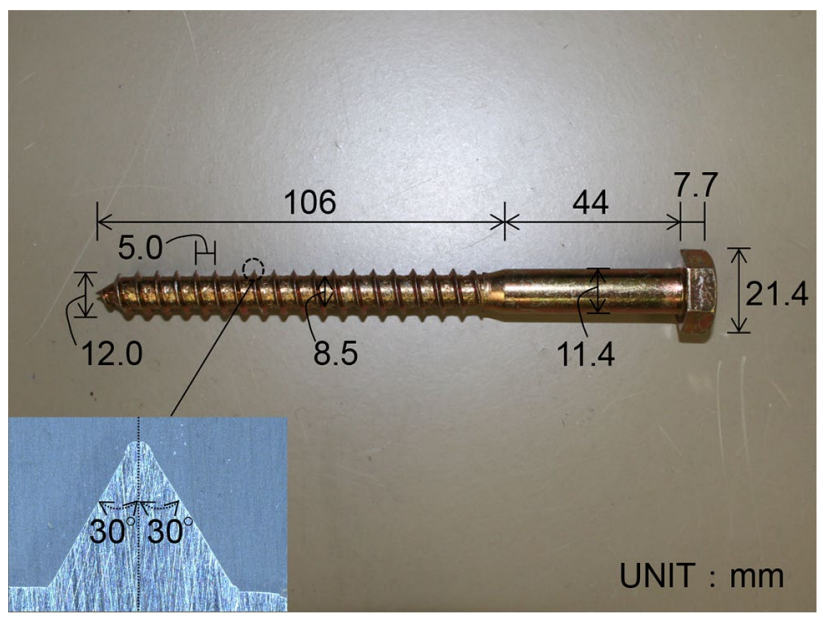

Fig. 2 Detailed dimensions of lag screw

round washer were $\varphi 32 \times 3.2 \mathrm{~mm}$ : its surface was galvanized then chromate treated. M12 lag screws were used, having a length of $150 \mathrm{~mm}$, pitch of $5.0 \mathrm{~mm}$ and thread 
half angle of $30^{\circ}$. (Detailed dimensions : see Fig. 2). During the tests, specimens were first set up in the testing device. Clamp force and thread torque were measured by means of a load cell wedged between the steel side plate and the main member, where load cell which have strain gages can be measured clamp force and torsional load. The tightening angle and tightening torque of the screw head were also measured. The screw was inserted into the wood perpendicular to the grain (from radial surface). The main member was held by a rotation-stopping component to limit any rotation due to tightening torque. The lag screw was tightened using a torque wrench until the screw head pressed against the round washer: i.e., until the axial force reached $15-40 \mathrm{~N}$. Screws were tightened at a speed of 1, 4, 10 and $20 \mathrm{rpm}$ until a reduction in clamp force was observed. Six specimens were tested in each condition.

\section{Results and discussion}

\section{The relationship of the tightening angle to the clamp force, tightening torque, and thread torque}

Figure 3 shows the typical relationships obtained for tightening angle versus clamp force, tightening torque, and thread torque. In $C$. japonica, tightening torque and thread torque follow the profile of clamp force: first rising, then falling after reaching a peak value. The initial, sharp rise in tightening torque and thread torque is likely the initial driving torque when the lag screw head pressed against the bearing surface. Similar behavior was observed in P. menziesii at all tightening speeds and in $C$. obtusa at tightening speeds of 10 and $20 \mathrm{rpm}$. In all test specimens of $C$. obtusa at tightening speeds of 1 and $4 \mathrm{rpm}$, however, jagged, 'sawtooth' patterns are apparent in the relationships between tightening angle and clamp force, tightening torque, and thread torque.
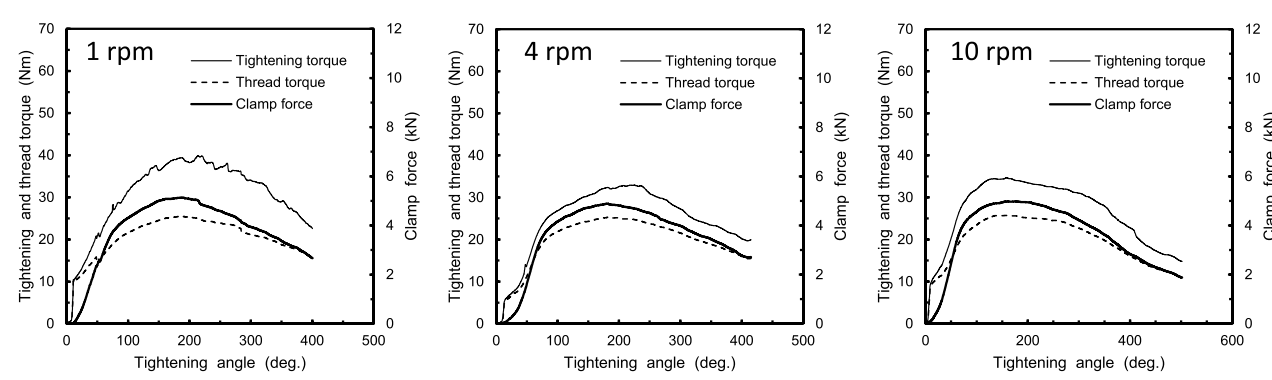

(a) Cryptomeria japonica
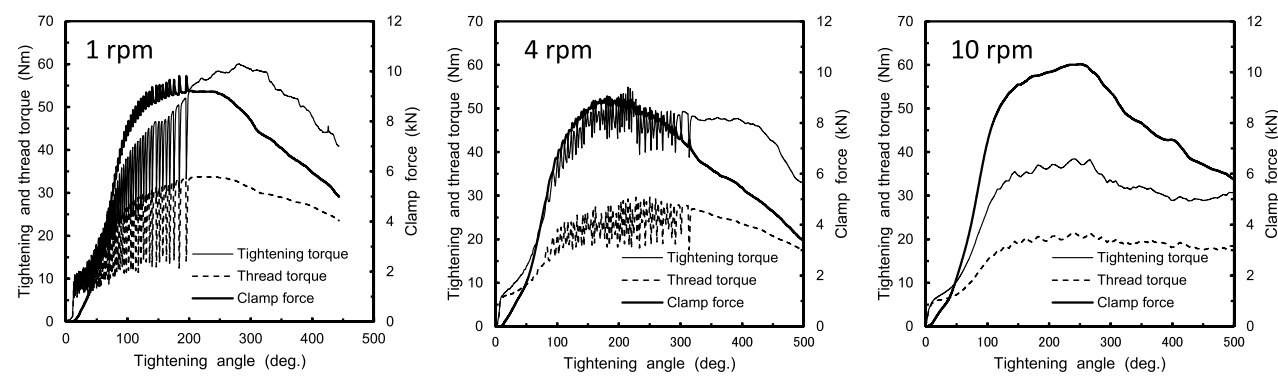

(b) Chamaecyparis obtusa
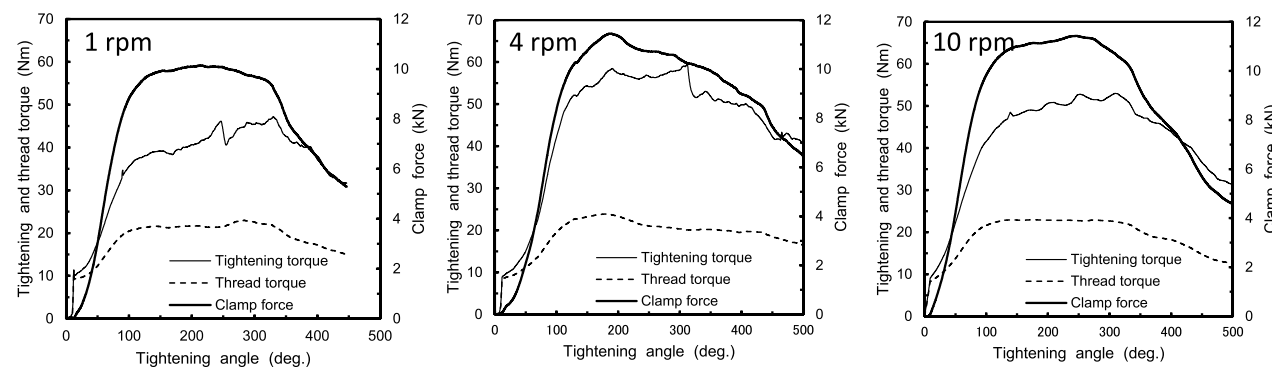

(c) Pseudotsuga menziesii
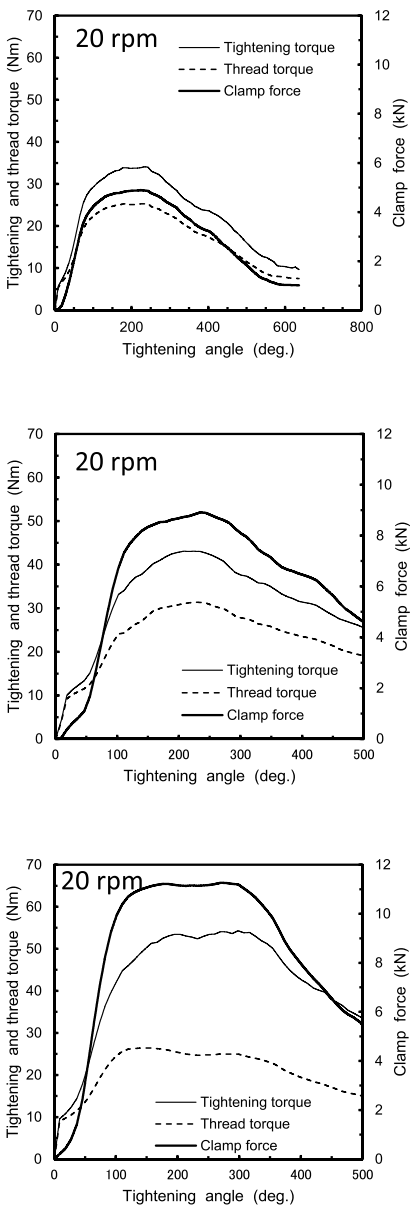

Fig. 3 Relationship between clamp force, tightening torque, thread torque, and tightening angle 
During the experiments, the wooden members were heard to creak, suggesting these fluctuations were due to stick-slip behavior between the lag screw thread and the main member. When major stick-slip occurs, the resultant clamp force is predicted to be highly variable, even if a torque control method were applied.

\section{Effect of tightening speed on tightening properties}

Tightening speed's effects on torque coefficient $K$, the coefficient of friction between threads $\mu_{\mathrm{th}}$, the coefficient of friction between bearing surfaces $\mu_{\mathrm{b}}$, the ultimate clamp force $F_{\text {max }}$, and the tightening torque at ultimate clamp force $T_{\text {max }}$ were investigated. $K, \mu_{\mathrm{th}}$, and $\mu_{\mathrm{b}}$ were, respectively, calculated using Eqs. (1), (2), and (3) below [8], where Eq. (2) is derived by neglecting the compressive deformation of the bearing surfaces:

$K=\frac{T_{\mathrm{f}}}{F_{\mathrm{f}} d}$,

$\mu_{\mathrm{th}}=\frac{\frac{T_{\mathrm{th}}}{F_{\mathrm{f}}}-\frac{P}{2 \pi}}{0.577 d_{2}}$,

$\mu_{\mathrm{b}}=\frac{T_{\mathrm{b}}}{0.5 D_{\mathrm{b}} F_{\mathrm{f}}}$,

where $F_{\mathrm{f}}$ is the clamp force; $T_{\mathrm{f}}$ is the tightening torque at $F_{\mathrm{f}}, d$ is the lag screw diameter $(=12 \mathrm{~mm}) ; T_{\text {th }}$ is the thread torque at $F_{\mathrm{f}} ; P$ is the pitch $(=5.0 \mathrm{~mm})$; and $d_{2}$ is the effective thread diameter $(=10.25 \mathrm{~mm}$ : calculated as the average of the major and minor diameter [(12.0 mm $+8.5 \mathrm{~mm}) / 2]$. $T_{\mathrm{b}}$ is the bearing surface friction torque at $F_{\mathrm{f}}$, calculated by Eq. (4) below [8]:

$T_{\mathrm{b}}=T_{\mathrm{f}}-T_{\mathrm{th}}$.

$D_{\mathrm{b}}$ is the equivalent frictional diameter on the bearing surface, as calculated by Eq. (5) below [8]:

$D_{\mathrm{b}}=\frac{D_{0}+d_{\mathrm{h}}}{2}$.

$D_{0}$ is the width across flats $(=18.8 \mathrm{~mm})$ and $d_{\mathrm{h}}$ is the bolt hole diameter of the washer $(=13.5 \mathrm{~mm})$.

The ratios $T_{\mathrm{f}} / F_{\mathrm{f}}, T_{\mathrm{th}} / F_{\mathrm{f}}$, and $T_{\mathrm{b}} / F_{\mathrm{f}}$ in Eqs. (1-3) were calculated as follows. First, each specimen's elastic range was established visually as the interval in the plot of tightening angle versus clamp force where the relationship appears linear. Then, $T_{\mathrm{f}} / F_{\mathrm{f}}, T_{\mathrm{th}} / F_{\mathrm{f}}$, and $T_{\mathrm{b}} / F_{\mathrm{f}}$ were calculated, respectively, for that interval in all specimens using the method of least squares.

Table 2 shows the tightening characteristic values of lag screw timber joints determined from the experiments. In $C$. japonica, $K$ and $\mu_{\mathrm{th}}$ appear to rise slightly with increasing tightening speed, while no noticeable differences are apparent for $\mu_{\mathrm{b}}, F_{\max }$, or $T_{\max }$. For C. obtusa, the aforementioned stick-slip behavior at tightening speeds of 1 and $4 \mathrm{rpm}$ meant that characteristic values could not be calculated for these

Table 2 Results of the tightening characteristic values

\begin{tabular}{|c|c|c|c|c|c|}
\hline $\begin{array}{l}\text { Conifer spe- } \\
\text { cies }(n=6)\end{array}$ & $K$ & $\mu_{\mathrm{th}}$ & $\mu_{\mathrm{b}}$ & $F_{\max }(\mathrm{kN})$ & $T_{\max }(\mathrm{Nm})$ \\
\hline \multicolumn{6}{|c|}{ Cryptomeria japonica } \\
\hline \multicolumn{6}{|c|}{$1 \mathrm{rpm}$} \\
\hline Ave. & 0.395 & 0.330 & 0.244 & 4.90 & 24.34 \\
\hline SD & 0.078 & 0.116 & 0.058 & 0.21 & 1.14 \\
\hline \multicolumn{6}{|l|}{$4 \mathrm{rpm}$} \\
\hline Ave. & 0.353 & 0.364 & 0.161 & 5.02 & 26.02 \\
\hline SD & 0.041 & 0.095 & 0.018 & 0.08 & 0.48 \\
\hline \multicolumn{6}{|l|}{$10 \mathrm{rpm}$} \\
\hline Ave. & 0.422 & 0.412 & 0.227 & 4.86 & 25.28 \\
\hline $\mathrm{SD}$ & 0.050 & 0.102 & 0.041 & 0.29 & 0.78 \\
\hline \multicolumn{6}{|l|}{$20 \mathrm{rpm}$} \\
\hline Ave. & 0.456 & 0.480 & 0.227 & 4.83 & 25.38 \\
\hline SD & 0.054 & 0.105 & 0.020 & 0.08 & 0.66 \\
\hline \multicolumn{6}{|c|}{ Chamaecyparis obtusa } \\
\hline \multicolumn{6}{|l|}{$1 \mathrm{rpm}$} \\
\hline Ave. & - & - & - & - & - \\
\hline $\mathrm{SD}$ & - & - & - & - & - \\
\hline \multicolumn{6}{|l|}{$4 \mathrm{rpm}$} \\
\hline Ave. & - & - & - & - & - \\
\hline $\mathrm{SD}$ & - & - & - & - & - \\
\hline \multicolumn{6}{|l|}{$10 \mathrm{rpm}$} \\
\hline Ave. & 0.264 & 0.116 & 0.211 & 10.22 & 22.56 \\
\hline $\mathrm{SD}$ & 0.030 & 0.046 & 0.035 & 0.57 & 1.64 \\
\hline \multicolumn{6}{|l|}{$20 \mathrm{rpm}$} \\
\hline Ave. & 0.281 & 0.226 & 0.155 & 9.34 & 26.61 \\
\hline $\mathrm{SD}$ & 0.063 & 0.096 & 0.029 & 1.26 & 3.48 \\
\hline \multicolumn{6}{|c|}{ Pseudotsuga menziesii } \\
\hline \multicolumn{6}{|c|}{$1 \mathrm{rpm}$} \\
\hline Ave. & 0.275 & 0.080 & 0.248 & 10.23 & 21.71 \\
\hline $\mathrm{SD}$ & 0.032 & 0.033 & 0.056 & 0.39 & 1.21 \\
\hline \multicolumn{6}{|l|}{$4 \mathrm{rpm}$} \\
\hline Ave. & 0.269 & 0.082 & 0.241 & 11.27 & 23.06 \\
\hline SD & 0.030 & 0.020 & 0.052 & 0.59 & 1.14 \\
\hline \multicolumn{6}{|l|}{$10 \mathrm{rpm}$} \\
\hline Ave. & 0.270 & 0.125 & 0.211 & 11.23 & 25.48 \\
\hline SD & 0.047 & 0.058 & 0.050 & 0.55 & 3.53 \\
\hline \multicolumn{6}{|l|}{$20 \mathrm{rpm}$} \\
\hline Ave. & 0.281 & 0.150 & 0.211 & 11.09 & 27.95 \\
\hline SD & 0.016 & 0.045 & 0.030 & 0.58 & 2.11 \\
\hline
\end{tabular}

$K$ torque coefficient, $\mu_{\text {th }}$ coefficient of friction between threads, $\mu_{\mathrm{b}}$ coefficient of friction between bearing surfaces, $F_{\max }$ ultimate clamp force, $T_{\max }$ tightening torque in ultimate clamp force, Ave. average, $S D$ standard deviation 

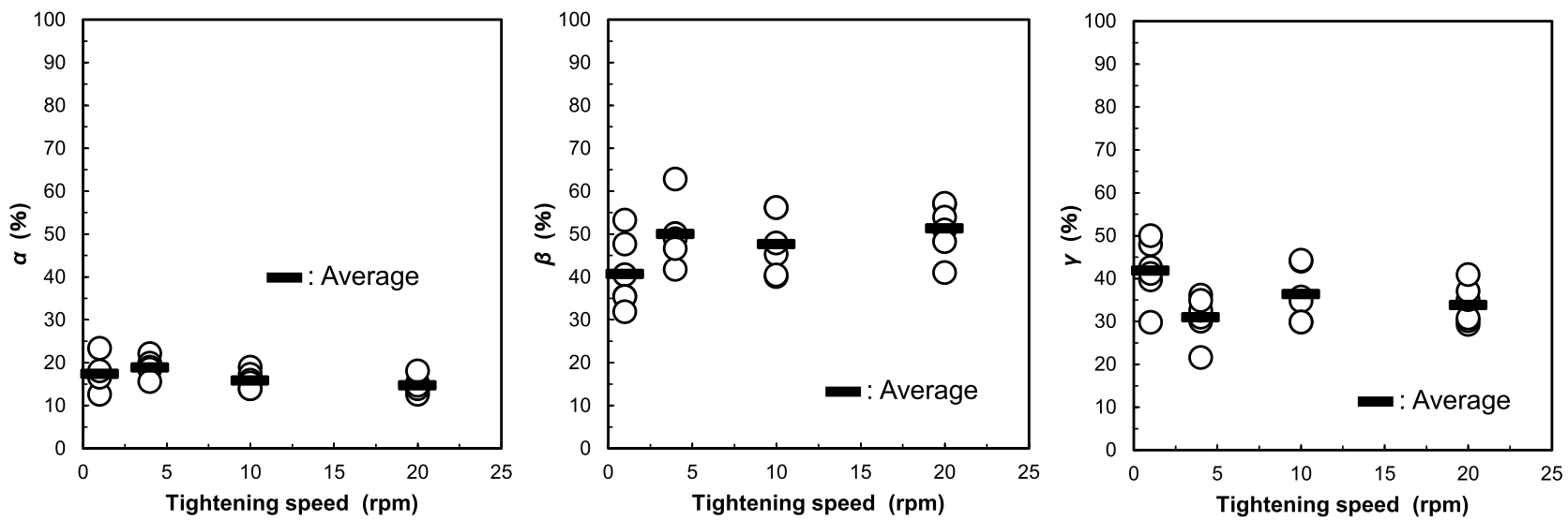

(a) Cryptomeria japonica
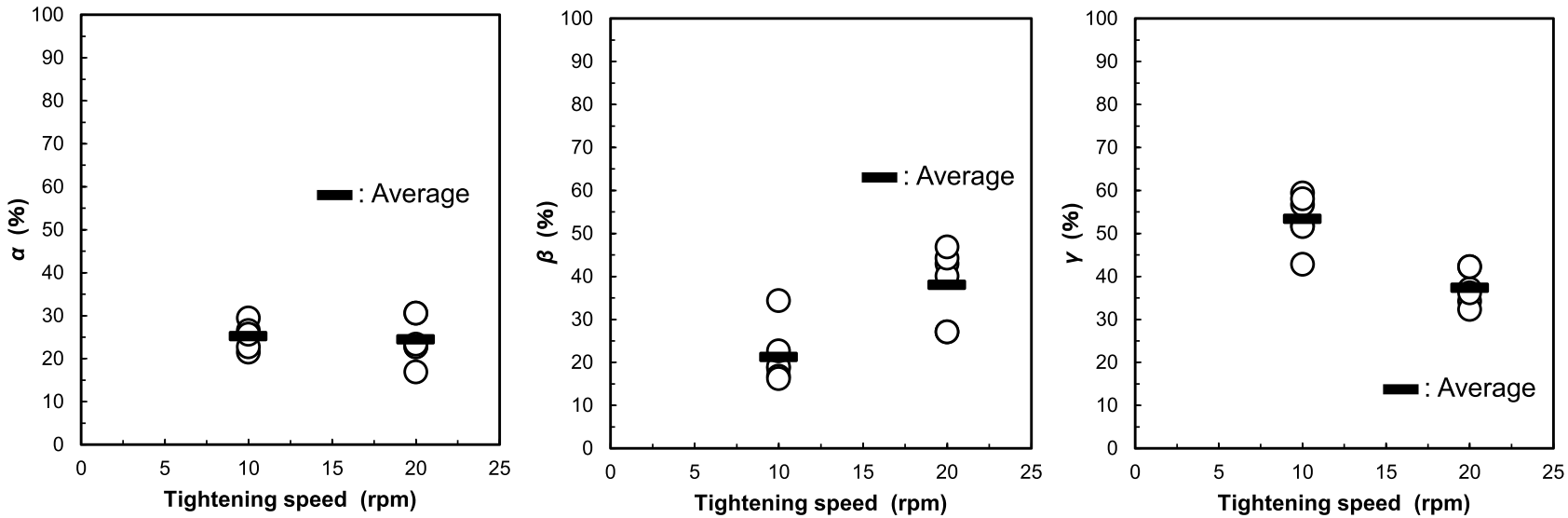

(b) Chamaecyparis obtusa
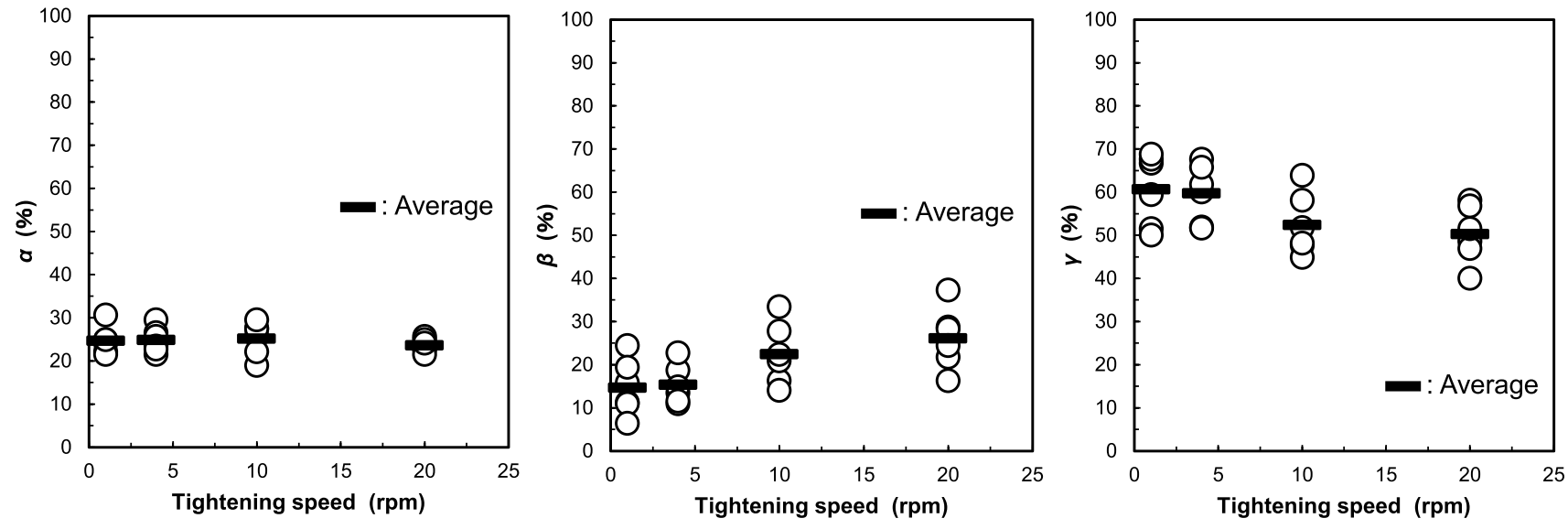

(c) Pseudotsuga menziesii

Fig. 4 Relative expenditure of tightening torque. $\alpha$ ratio of torque expended on tightening, $\beta$ ratio of torque expended on thread friction, $\gamma$ ratio of torque expended on bearing surface friction

conditions; data were only obtained for tightening speeds of 10 and $20 \mathrm{rpm}$. Under these conditions, $K$ and $\mu_{\text {th }}$ tended to be lower than in the corresponding condition for $C$. japonica. In P. menziesii specimens, increasing tightening speed caused no major changes to $K, \mu_{\mathrm{b}}$, or $F_{\text {max }}$, but elevated $\mu_{\text {th }}$ and $T_{\max }$ slightly. The $\mu_{\mathrm{th}}$ at $20 \mathrm{rpm}$ is about $30 \%$ that measured for $C$. japonica specimens at the same speed. For this result, it is considered that no noticeable differences are 
apparent for $T_{\max }$ in $P$. menziesii and $C$. japonica. Here, $K$ can also be expressed by Eq. (6) below [9]:

$K=\frac{1}{d}\left(\frac{P}{2 \pi}+0.577 \mu_{\mathrm{th}} d_{2}+0.5 \mu_{\mathrm{b}} D_{\mathrm{b}}\right)$.

The terms inside parentheses in Eq. 6 show the breakdown of torque consumption: the first term is the torque expended on clamp load of thread pitch's inclined plane, the second term is the torque expended on thread friction, and the third term is the torque expended on bearing surface friction [4]. The ratios of these component torques to total torque were calculated using the data in Table 2 and, respectively, labeled $\alpha, \beta$, and $\gamma$. Figure 4 shows the relationships of tightening speed with $\alpha, \beta$, and $\gamma$. Tightening speed had no major effect on $\alpha$ in $C$. japonica, $C$. obtusa, and $P$. menziesii specimens (mean: 17, 25, and 25\%, respectively). We have previously reported that bolted timber joints generally have an $\alpha$ of around 8-10\% [4]. However, the value we measured for lag screw joints in this study is over double that, seeming to signify that lag screws convert clamp force into torque more efficiently than do bolts. In $C$. japonica, $\beta$ appear to rise slightly with increasing tightening speed, while no noticeable differences are apparent for $\gamma$. In P. menziesii specimens, however, faster tightening speeds caused $\beta$ to increase and $\gamma$ to decrease with increasing tightening speed: at $20 \mathrm{rpm}$, they were 25 and $50 \%$ on average, respectively, with $\gamma$ about twice as large as $\beta$.

The findings above suggest that in lag screw timber joints with steel side plates, the tightening speed's effects on $K, \alpha$, $\beta$, and $\gamma$ differ depending on the wood species from which the main timber member is made. While $K$ increases slightly at faster tightening speeds in $C$. japonica, it is unaffected in $P$. menziesii. Moreover, $\alpha$ is over twice as high in all three wood species than in similar bolted timber joints. Finally, $\beta$ and $\gamma$, respectively, increase and decrease with increasing tightening speed in $P$. menziesii, such that $\gamma$ becomes greater than $\beta$. Incidentally, lubricant is often applied to the threads and bearing surfaces of metallic bolted joints, to eliminate the effects of tightening speed on $K$ as much as possible, as well as to improve workability by lowering the frictional coefficient. We did not use lubricant in our experiments. However, given that tightening speed had no effect on $K$ in P. menziesii, and that this species' $\mu_{\mathrm{th}}$ was lower than the others, a torque control method using torque wrench or other tool could likely be applied under unlubricated conditions. However, as can be seen from Table 2, variability in $K$ and each of the frictional coefficients is inevitable when applying a torque control method. Therefore, when deciding on $K$ for a torque control method, it is important that variability in $K$ is appropriately evaluated.

\section{Conclusions}

Using the main timber members made from Cryptomeria japonica, Chamaecyparis obtuse and Pseudotsuga menziesii, we subjected lag screw timber joints with steel side plates to tightening tests at four different tightening speeds $(1,4,10$, and $20 \mathrm{rpm}$ ), to investigate the effects of tightening speed and wood species on the torque coefficient $K$. The major findings determined within the scope of this study are as follows:

(1) At tightening speeds of 1 and $4 \mathrm{rpm}$, major stick-slip behavior was observed in the relationships of tightening angle with clamp force, tightening torque, and thread torque in C. obtusa.

(2) Torque coefficient $(K)$ rose with increasing tightening speed in $C$. japonica; however, it exhibited no effects due to it in P. menziesii.

(3) The ratio of torque expended on tightening $(\alpha)$ was unaffected by tightening speed: on average, it was $17 \%$ in C. japonica, $25 \%$ in C. obtusa, and $25 \%$ in P. menziesii.

(4) In P. menziesii, the ratio of torque expended on thread friction $(\beta)$ rose with increasing tightening speed, while the ratio of torque expended on bearing surface friction $(\gamma)$ fell: at $20 \mathrm{rpm}, \beta$ was about half of $\gamma$.

The findings above show that tightening speed's effects on the torque coefficient and tightening properties of lag screw timber joints with steel side plates differ depending on the wood species of the timber component. In lag screw joints of $P$. menziesii specimens, however, tightening speed had no effect on torque coefficient $K$, suggesting the feasibility of a torque control method using torque wrench or other tool for this kind of wood.

Acknowledgements This work was supported in part by the Science and Technology Research Promotion Program for Agriculture, Forestry, Fisheries and Food Industry.

\section{References}

1. Kobayashi K (2015) Present and future tasks for screw joints in timber structures (in Japanese). Mokuzai Gakkaishi 61(3):162-168

2. Japan Timber Engineering Society (2012) ISBN 978-4-75301856-7 C3052. Inoue-shoin Co. Ltd., Tokyo, pp 173-175

3. Sayed AN, Saravanan G, Ramanathan MR, Gary CB (2006) Effect of tightening speed on the torque-tension and wear pattern in bolted connections. J Press Vessel Technol 129(3):426-440

4. Matsubara D, Nakano T, Shimada M, Funada R, Hattori N (2015) Effect of tightening velocity on the torque coefficient of timber jointing with bolts (in Japanese). Mokuzai Gakkaishi 61(1):33-39

5. Wakashima Y, Shimizu H, Fujisawa Y, Ishikawa K, Kitamori A, Matsubara D (2016) High dampimg shear walls using wood 
friction joints. In: Proceeding of world conference on timber engineering, Vienna, Austria

6. Matsubara D, Wakashima Y, Fujisawa Y, Shimizu H, Kitamori A, Ishikawa K (2017) Tightening torque calculation method for plastic clamp force of bolted timber joints (in Japanese). Mokuzai Gakkaishi 63(4):162-175

7. Matsubara D, Wakashima Y, Fujisawa Y, Shimizu H, Kitamori A, Ishikawa K (2017) Relationship between clamp force and pull-out strength in lag screw timber joints. J Wood Sci 63:625-634
8. JIS B1084-2007 (2008) Fasteners-Torque/clamp force testing (in Japanese). Japanese Standard Association, Tokyo, p 833

9. JIS B1083-2008 (2008) General rules for tightening of threaded fasteners (in Japanese). Japanese Standard Association, Tokyo, p 806 